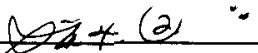

JUN 231999 ENGINEERING DATA TRANSMITTAL

Page 1 of 1 1. EDT 627452

\section{To: (Receiving Organization)}

Distribution

5. Proj./Prog./Dept./Div.:

106029 105-AN Corrosion Probe

\section{Originator Remarks:}

This document satisfies the requirements of Milestone DI of FY 1999

TTP\# RL0-8-WT-21.

\section{Receiver Remarks:}

11A. Design Baseline Document? $\bigcirc$ Yes $O$ No

Advances in data analysis techniques for Hanford's corrosion monitoring systems

3. From: (Originating Organization)
RPP Equipment Engineering 74700
$\begin{aligned} & \text { 6. Design Authority/Design Agent/Cog. Engr.: } \\ & \text { Cog. Eng.: G. L. Edgemon }\end{aligned}$

\begin{tabular}{|l} 
4. Related EDT No.: \\
627452 \\
\hline 7. Purchase Order No.: \\
N/A \\
\hline 9. Equip./Component No:
\end{tabular}

$\mathrm{N} / \mathrm{A}$

10. System/BIdg./Facility:

$\mathrm{N} / \mathrm{A}$

12. Major Assm. Dwg. No.:

$\mathrm{N} / \mathrm{A}$

13. Permit/Permit Application No::

N/A

14. Required Response Date:

$\mathrm{N} / \mathrm{A}$

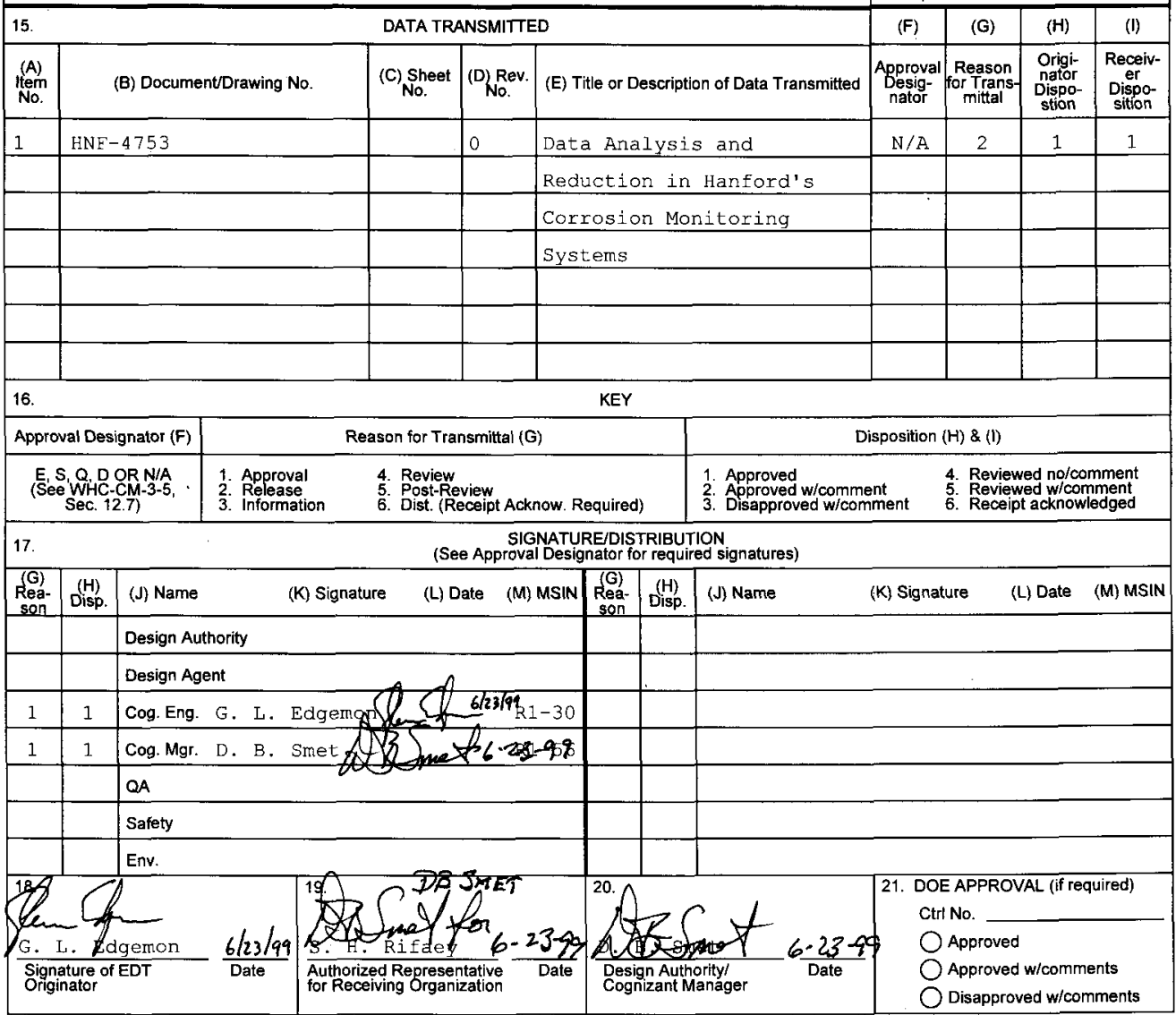




\title{
Data Analysis and Reduction in Hanford's Corrosion Monitoring Systems
}

\author{
G. L. Edgemon \\ Lockheed Martin Hanford Corporation \\ Richland, WA 99352 \\ U.S. Department of Energy Contract DE-AC06-96RL13200
Org Code: $74700 \quad$ Charge Code: 106029
B\&R Code: Ew4 $010000 \quad$ Total Pages: 17 \\ EDTIIECN: $627452 \quad$ UC: 2030
}

Key Words: corrosion probe, multi-function probe, electrochemical noise, data analysis

Abstract: Corrosion probe data analysis techniques. This document meets the requirements of Milestone D1 of EY 1999 TTP\# RLO-8-WT-21.

TRADEMARK DISCLAIMER. Reference herein to any specific commercial product, process, or service by trade name, trademark, manufacturer, or otherwise, does not necessarily constitute or imply its endorsement, recommendation, or favoring by the United States Government or any agency thereof or its contractors or subcontractors.

Printed in the United States of America. To obtain copies of this document, contact: Document Control Services, P.O. Box 950, Mailstop H6-08, Richland WA 99352, Phone (509) 372-2420; Fax (509) 376-4989.
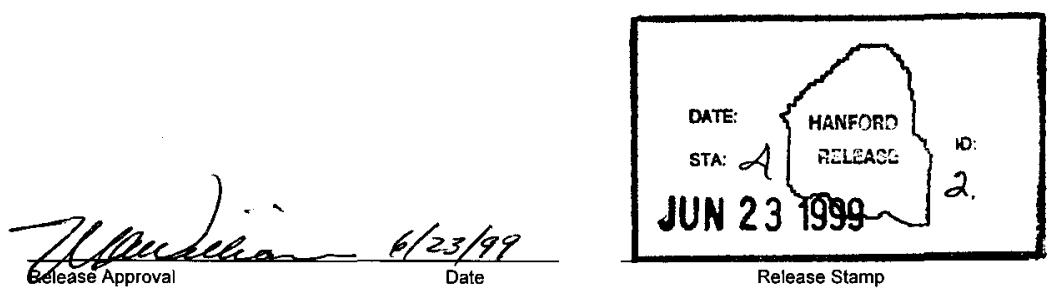

Approved For Public Release 
HNF-4753, Rev. 0

\section{INTRODUCTION AND BACKGROUND}

Underground storage tanks made of mild steel are used to contain radioactive waste generated by plutonium production at the Hanford Site. Corrosion of the walls of these tanks is a major issue. Corrosion-related failure of waste tank walls could lead to the leakage of radioactive contaminants to the soil and groundwater. It is essential to monitor corrosion conditions of the tank walls to determine tank integrity and ensure safe waste storage until retrieval and final waste disposal can be accomplished. Corrosion monitoring/control is currently provided at the Hanford Site through a waste chemistry sampling and analysis program. In this process, tank waste is sampled, analyzed and compared to a selection of laboratory exposures of coupons in simulated waste. Tank wall corrosion is inferred by matching measured tank chemistries to the results of the laboratory simulant testing. This method is expensive, time consuming, and does not yield real-time data. A project to improve the Hanford Site's corrosion monitoring strategy was started in 1995 .

A small number of techniques have previously been tried at Hanford and elsewhere within the DOE complex to determine the corrosivity of nuclear waste stored in underground tanks [1]. Coupon exposure programs, linear polarization resistance (LPR), and electrical resistance techniques have all been tried with limited degrees of success. These techniques are most effective for monitoring uniform corrosion, but are not well suited for early detection of localized forms of corrosion such as pitting and stress corrosion cracking (SCC). Pitting and SCC have been identified as the most likely modes of corrosion failure for Hanford Double Shell Tanks (DST's) [2-3].

Over the last 20 years, a new corrosion monitoring system has shown promise in detecting localized corrosion and measuring uniform corrosion rates in process industries [4-20]. The system measures electrochemical noise (EN) generated by corrosion. The term EN is the term used to describe low frequency fluctuations in current and voltage associated with corrosion. In their most basic form, EN-based corrosion monitoring systems monitor and record fluctuations in current and voltage over time. Laboratory studies and field applications have shown that different types of corrosion create different patterns of current and voltage fluctuations (i.e.: EN). By monitoring the EN produced by corrosion on electrodes immersed in Hanford waste tanks, waste tank corrosion conditions can be observed in real-time.

A two-year laboratory study was started at Hanford in 1995 to provide a technical basis for using EN-based systems to monitor corrosion in Hanford's nuclear waste tanks [21]. Based on this study, a prototype system was constructed and deployed in DST 241-AZ-101 in August, 1996 [22]. Based on the successful demonstration of this prototype, a full-scale system was designed and installed into DST 241-AN-107 in September 1997 [23]. A second-generation full-scale system similar to the 241-AN-107 system was designed, fabricated and installed in 241-AN-102 in August 1998 [24]. A third-generation full-scale system with numerous design improvements is scheduled for deployment into 241-AN-105 in fiscal year 1999 [25].

All of Hanford's EN-based corrosion monitoring systems have at least one thing in common with EN-based systems used in other industries: they are all capable of producing extremely large amounts of data. The Hanford systems have generated nearly 580 million points of data to date. 
An obvious challenge in working with EN-based systems is data analysis and reduction. This report documents advances in Hanford EN data analysis techniques starting with the laboratory corrosion monitoring systems used in the proof-of-principle testing program and ending with the system currently being designed for deployment into 241-AN-105 in FY 1999.

\section{DATA ANALYSIS IN LABORATORY EN SYSTEMS}

The bulk of EN proof-of-principle tests were performed with a CMS100/PC3 electrochemical measurement system manufactured by Gamry Instruments. ${ }^{1}$ This system facilitated long-term test exposures by allowing the operator to pre-program test length and run time. Once started, the system ran until stopped by the operator, interrupted by system software malfunction, or shut down by power failure. Potential and current EN were recorded once per second on the active channel. In the testing program, data were typically collected for 600 seconds per file. After 600 seconds, the active file closed and a new file was created. This process repeated up to the conclusion of testing. Post-collection data analysis was manually performed using internally developed statistical analysis software and a spreadsheet program such as Microsoft Excel. ${ }^{2}$

In practice, a test operator set up an experiment, connected the test wires from the test cell to the corrosion monitoring hardware and launched the software to collect the data. At the conclusion of testing (from several hours to several months), raw data points were manually stripped out of the raw data files, copied into a spreadsheet program and plotted against the time of exposure. A typical raw data file is shown in Figure 1.

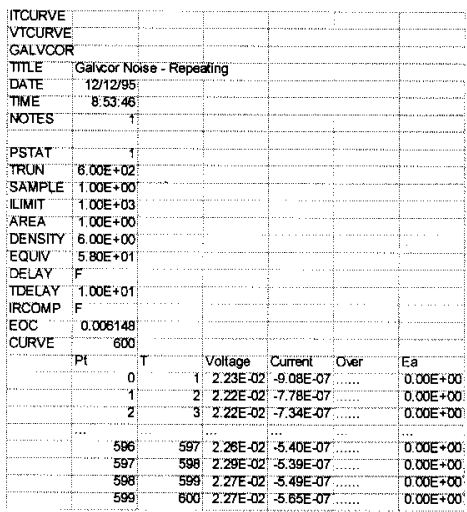

Figure 1: 600 point Gamry raw data file collected during a typical EN experiment (mid-section of data removed for presentation

\footnotetext{
${ }^{t}$ Gamry, CMS100, and PC3 are trademarks of Gamry Instruments, Inc., Warminster, Pennsylvania.

${ }^{2}$ Microsoft and Excel are registered trademarks of Microsoft Corporation, Redmond, Washington.
} 
A typical raw data plot is shown in Figure 2. The process of manually inspecting each raw data file quickly proved to be too time consuming and a new data analysis routine was developed. Instead of moving directly into raw data file analysis at the conclusion of testing, raw data were first manually stripped out of a selection of raw data files and subjected to various statistical analyses. These statistical data points were then plotted against test time. Plots of statistical data vs. time proved to be very useful in identifying regions of change in corrosion behavior. By identifying time periods of change in corrosion behavior, raw data file inspection was limited to interesting areas identified by the statistical analyses.

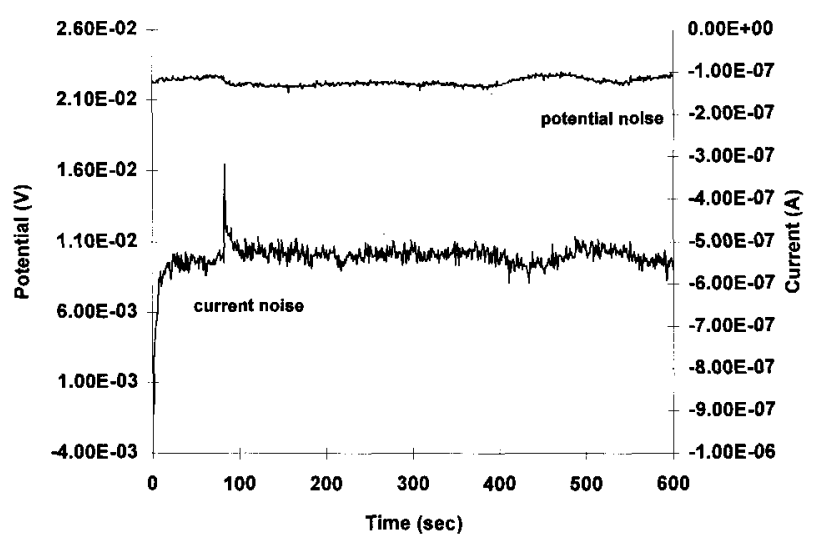

Figure 2: 600 point Gamry raw data plot created by manually importing data shown in Figure 1 into Microsoft Excel for presentation.

Although an improvement over strict raw data analysis, the large number of manual operations involved in the creation of statistical data analysis files also proved to be unacceptable and software was written to automate the statistical analysis process. In practice, the test operator placed the new statistical analysis software executable file in the same directory with all the raw data files from the test of interest. When launched, the new statistical analysis software stripped out raw data, performed a host of statistical analyses on the data, then wrote the results of the analyses to a file that was imported into a spreadsheet program for plotting and further analysis. The application of software driven statistical analysis marked the first real advance in automating the entire EN data analysis process. An output file from the early statistical analysis software is shown in Figure 3. A plot of a typical statistical file is shown in Figure 4. 


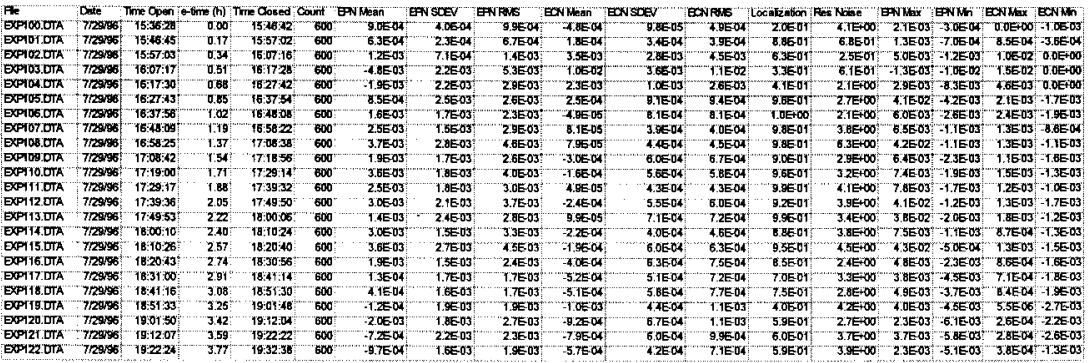

Figure 3: Top section of output file from internally developed statistical analysis software

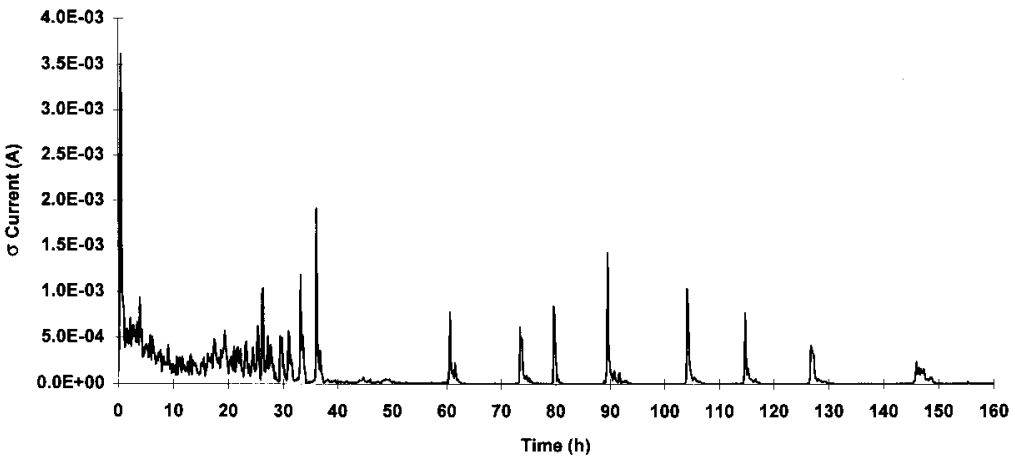

Figure 4: Plot of standard deviation of current data shown in Figure 3 (plot shows SCC of mild steel)

\section{1-AZ-101 CORROSION MONITORING SYSTEM}

Data analysis techniques developed during the proof-of-principle testing were directly applied to analysis of EN data collected from the 241-AZ-101 prototype corrosion monitoring system. The 241-AZ-101 system utilized the Gamry Instruments CMS100/PC3 electrochemical measurement system previously used in the proof-of-principle testing. An eight channel multiplexer was added to the system to provide a multi-channel monitoring capability. Data were collected sequentially on three electrode arrays situated on a probe placed inside 241-AZ-101 using three channels of the multiplexer. Potential and current measurements were recorded once per second 
on the active array. Data were typically collected for 600 seconds per channel. Post-collection data analysis was performed using the statistical analysis software developed during the proofof-principle testing in conjunction with Microsoft Excel. Data acquisition began following electronics package installation on August 8, 1996. A prototype probe raw data plot showing uniform corrosion is shown in Figure 5. A prototype probe raw data plot showing pitting corrosion after a large water addition is shown in Figure 6. A plot of statistical data taken from the prototype probe is shown in Figure 7 . Three reports were generated to document the performance of this system $[22,26,27]$.

Although numerous difficulties were encountered in transporting data from the 241-AZ-101 corrosion monitoring system control computer located in the field to data analysis computers located outside the tank farm, the data analysis techniques developed during the proof-ofprinciple testing proved to be acceptable for handling and analyzing prototype probe data. At this point in the corrosion probe development program, a single researcher could process the data being generated from the 241-AZ-101 system with the software tools developed for laboratory data analysis.

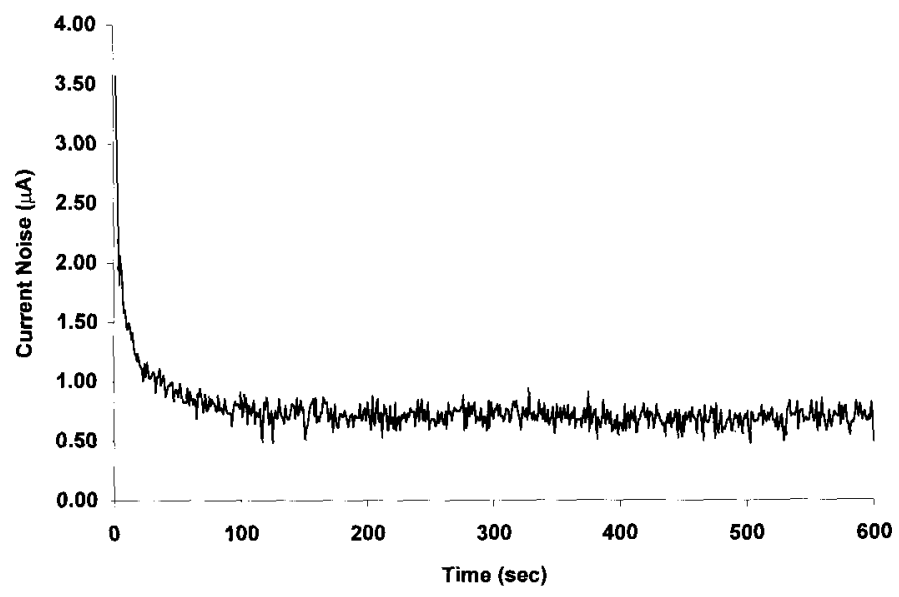

Figure 5: Current noise collected from uniform corrosion in 241-AZ-101 


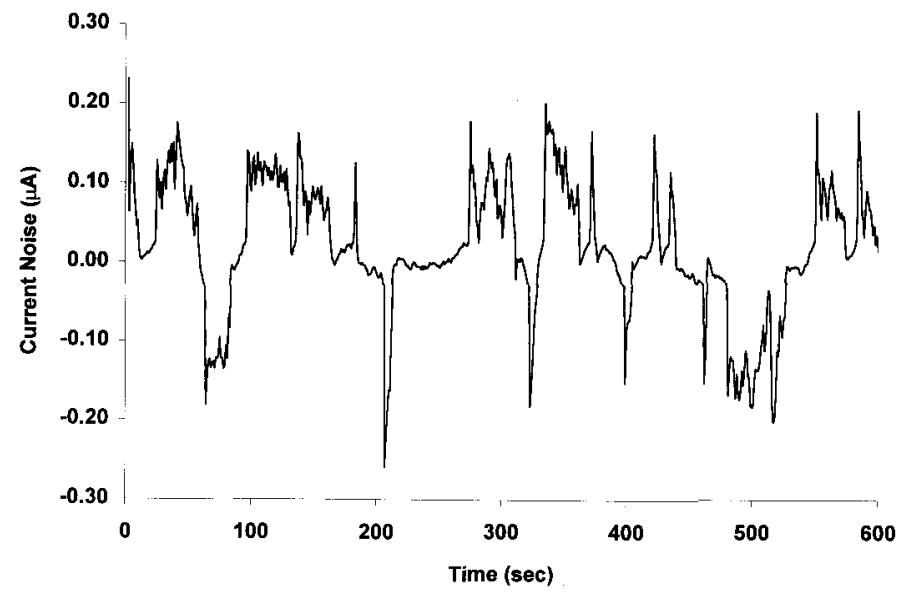

Figure 6: Current noise in 241-AZ-101 during pitting induced by a large water addition

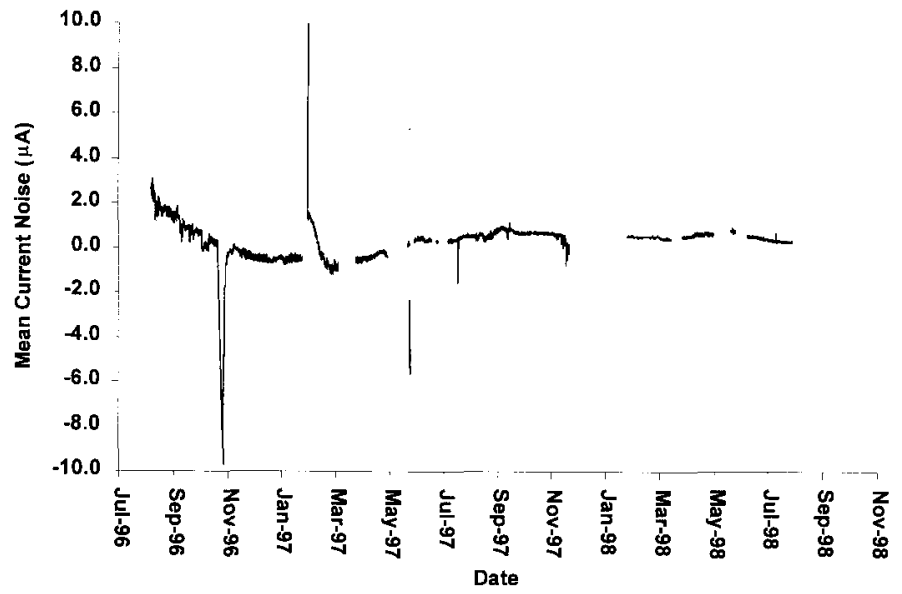

Figure 7: Statistical data showing effect of large water additions in 241-AZ-101 (spikes mark disturbances due to water additions) 


\section{1-AN-107 CORROSION MONITORING SYSTEM}

Although the Gamry equipment used in the laboratory proof-of-principle testing and the 241-AZ101 systems demonstrated that an EN-based system could likely be used to monitor waste tank corrosion, the system hardware was deemed to have too low a level of potential (voltage) sensitivity. Therefore, the Gamry equipment was not used on any other system following the 241-AZ-101 installation. For the 241-AN-107 system, a DENIS eight channel corrosion monitoring system and associated software manufactured by Capcis March Limited (CML) was procured and installed. ${ }^{3}$

Like the Gamry system, the CML system was programmed to run continuously after startup. Current and potential data were logged every second into files of 600 seconds each. At the conclusion of a 600 -second monitoring period, the active file was time/date stamped and stored on the controlling computer's hard drive. Data collection on the next channel then commenced. Data were collected sequentially on eight channels connected to eight electrode arrays located on a probe installed in the waste tank. Once started, the system ran until stopped by the operator, interrupted by system software malfunction, or shut down by power failure. Several months after installation, the system was reconfigured and upgraded to write files directly to the Hanford Local Area Network (HLAN) to facilitate analysis work on any other networked computer.

A typical output file from the CML system is shown in Figure 8. A typical output plot is shown in Figure 9. Although current and potential were measured simultaneously, raw data were written in a single column in the data file. Potential values were listed prior to current values. Statistical parameters were stored at the end of the column shortly before the file was closed. Additional software was later provided by CML to strip the statistical values out of each raw data file and collect them into a database where they could be plotted for further analysis. A typical statistical analysis output data file is shown in Figure 10.

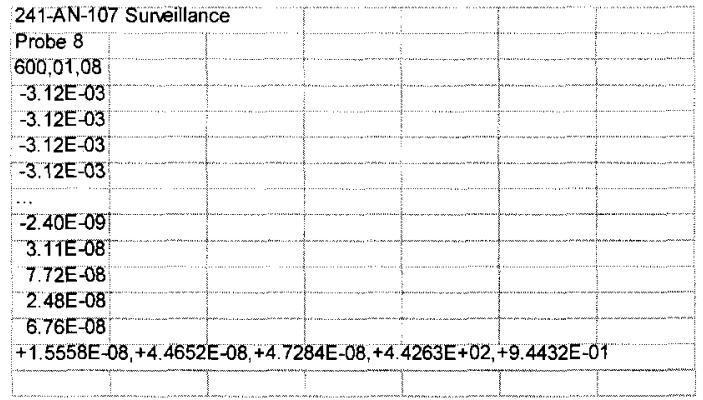

Figure 8: 600 point CML raw data file collected during a typical EN experiment (mid-section of data removed for presentation.

\footnotetext{
${ }^{3}$ DENIS is a registered trademark of Capcis March Ltd., Manchester, UK.
} 


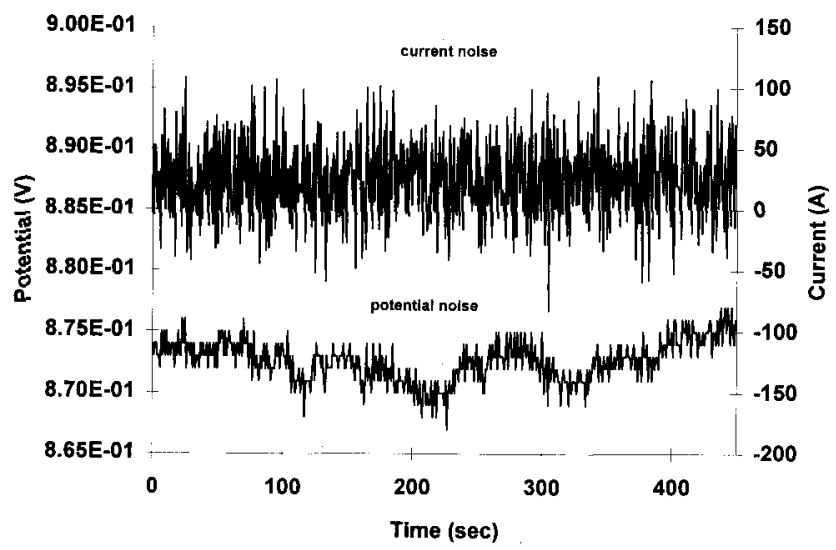

Figure 9: CML raw data plot created by manually importing data into Microsoft Excel for presentation.

\begin{tabular}{|c|c|c|c|c|c|c|c|c|c|c|c|c|c|c|}
\hline Dste & Time & Date 8 & Job Title & rabe Title & EPN Min & & & & & & & & & \\
\hline & $21: 11: 00$ & & 241.AN-107 Suneil/ance & Proba 8 & $5.46 E-12$ & . $40 \mathrm{E}-02$ & $5.42 E-02$ & $-5.42 E+01$ & $1.52 E-04$ & $1.52 \mathrm{E}-0 \mathrm{~T}$ & $5.42 E-02$ & $9.36 \mathrm{E}-08 \%$ & & \\
\hline & $2235: 00$ & 9/16/97 22:35 & 5.241-AN-107 Sundilfaicice & Probe o & $5.46 E X 02$ & $-5,42 \mathrm{E}-02$ & 5 AAED2: & $-5,44 E+01$ & Q.40ED05 & $9.40 E-02$ & $544 E-02$ & 8.26E-08: & 3.U6E-DT & RTIE-07 \\
\hline $16-\$$ & $23: 5900$ & 9/16/87 23: & 107 Suneillance & Probe 8 & $5.58 E-0$ & & $-5.55 \mathrm{E}-02$ & $-5.55 E+01$ & $1.65=-04$ & T.65E-01 & 5.55E-02 & I $8.16 E-09:$ & 1.77E-07 & $7.72 \mathrm{E}-07$ \\
\hline $17-50 \mathrm{p}-07$ & $1: 22: \infty$ & Q & 241 -AN-107 Sunbillanice & Probe 8 & 5.26E-02 & $-521 \mathrm{E}-02$ & $-5.23 \mathrm{E}-02$ & $-5.23 \mathrm{E}+01$ & $1.44 E-04$ & $144 E-01$ & $523 E-02$ & $7.39 E-08:$ & $2.74 E-0 T$ & 1.76E-07 \\
\hline & $2: 4600$ & $517 / 972: 46$ & 5 241-AN-107 Sunvillañice & Probe 8 & $5.15 E-02$ & -5.11E-02: & $-5.12 E-02$ & $-5.12 E+01$ & Q.91E-05 & - G.3E-02 & $5.12 E-02$ & $6.47 E-08$ & $2.84 E=07$ & 1.30E-07 \\
\hline 17-Sop-97: & 40900 & $917 / 97409$ & 9241-AN1 107 Süwellance & Probs 8 & & $-5.02 \mathrm{E}-02$ & $-5.04 E-02$ & $5.04 E+01$ & 9.58505 & $9.58 E-02$ & $5.04 E-02$ & $7.01 E-08$ & $2.73 E-07$ & $1.83 E-07$ \\
\hline 17-Sep-s7 & 53300 & $9 / 17 / 975: 33$ & 3.241-AN-107 Suneillanco & Probe $B$ & $5.02 E-02$ & $-499 \mathrm{E}-02$ & 5.00 & $E+04$ & & & & & 28 & $6 E-07$ \\
\hline & 6.5700 & $917 / 976.57$ & 7 :241-AN-107 Süridilince & Probo 8 & $4.92 E-02$ & $4.90 E-02$ & $-190 E-02$ & $4.90 \mathrm{E}+01$ & 6.23E-05 & 8.23E-02 & 490E-02 & (1) B. $19 E-08$ & $2.87 E-07$ & 1.83E-07 \\
\hline 17-5-5-97 & 8:20:00: & $9717 / 978: 20$ & 0221-AN-107 Sunvellance & Probo 0 & $-4,84$ & A.81E-02 & $+B 2 E-02$ & 4. BEE & 9.62E-03 & 9.62E-D2 & 4.82E-02 & $8.70 \mathrm{E}=08$ & 2.98E-07 & TETE-07 \\
\hline 17-\$ep-97 & 9:44:00: & $9 / 17 / 979: 44$ & 4 241-AN-107 Suneillance & Probe a & $481 E-02$ & $4.79 E-02$ & 4 AOE- -02 & $4 . \mathrm{BOE}+01$ & $E-05$ & & 4.80E-02 & B. $37 \mathrm{TE}-0 \mathrm{~B}$ & 3.0 & DE-07 \\
\hline $\boldsymbol{H} \mathbf{s}$ & 11:23:00 & $9 / 17 / 9711: 23$ & 3241-AN-107 Suneillance & Probbo 8 & $4,74 E-02$ & $4.70 \mathrm{E}-02$ & $-71 \mathrm{E}-02$ & $4.71 E+01$ & 1. 12E-04 & $1.12 E-01$ & $4.71 \mathrm{E}-02$ & 6.33E- & 2. $800-07$ & 1.71E-07 \\
\hline 17-Sop-97: & 12:46:00 & $9 / 77 / 97$ 12:46 & 6:241-AN-107 Suneillbirice & Probe 8 & $480 \mathrm{E}-2$ & $4.77 E-02$ & 4. TBE-02 & $-4.78 E+01$ & 84E-05 & 6.54E-02 & $4,7 \mathrm{AE}-02$ & 7.71E-OS & 2.64E-07? & 1.70E-07 \\
\hline 17-Sop-97 & $14: 10: 00$ & $9 / 17 / 9714: 10$ & D:241-AN-167'Sunineillance & Probe 8 & A6TED2 & 4.6AE-02: & 4:65E-02: & $4.65 E+01$ & $7.67 E-05$ & $7.67 \varepsilon-02$ & $E, Q 2$ & 008 & $E-07:$ & $1.62 \mathrm{E}-07$ \\
\hline 17-Sop-57 & 153400 & $9 / 17 / 9775: 34$ & 4 241-AL-107 Sunveillínce & Prichó 8 & A, 68E-02 & $4.57 \mathrm{E}=02$ & - 4.62E-02: & $-62 E+01$ & $3.48 E-04$ & $3.48 E-01$ & $462 \mathrm{E}-02$ & $7.65 E-08$ & $2.85 E-07$ & 1.74E-07 \\
\hline 17-Sep-9 & $16: 5700$ & $5 / 17 / 977965$ & 7241-4N-107 Suneillanicb & Priabe 8 & $B E=02$ & 45 & $-4.565,02$ & $-4.55 E+01$ & $9.62 E-05$ & $8.52 E-02$ & 4.56E 0 & $7.63 E-08:$ & $2.54 E-07$ & 1.55E- -87 \\
\hline & $.18: 21: 00$ & 9/17/97 18:21 & $1241-4 / 4-107$ sunvellile & Pröbe 8 & $4,59 \mathrm{E}-02$ & 4.53E- $-2:$ & $5 E-02$ & $4.55 E+01$ & $1.74 E-04$ & $74 E-01$ & 4.55E-012 & $4.26=-18$ & 2.GZE-07: & T.61E-07 \\
\hline
\end{tabular}

Figure 10: Top section of output file from CML statistical analysis software

In early FY 1999, problems relating the time/date stamp used by the CML system and the upcoming turn of the century were discovered. It was determined that the CML system would no longer be able to perform its data manipulation operations after December 31, 1999. An ENbased system manufactured by Petroleum Research Production, Ltd. using software created by Corrosion \& Condition Control, Ltd. was selected and procured to replace the existing CML 
HNF-4753, Rev. 0

system. Details of this system can be found in this report in the discussions related to the 241AN-102 and 241-AN-105 systems.

\section{1-AN-102 CORROSION MONITORING SYSTEM}

Although the general performance of the CML system was acceptable, CML Ltd. quit producing the DENIS system and went out of business in 1997. A competitive request for proposal (RFP) was issued in FY 1998 to locate a new source for EN-based equipment. The following system performance requirements were placed in the RFP:

- When connected to an appropriate set of electrodes, the corrosion monitoring equipment must be capable of collecting current and voltage electrochemical noise (EN) data in an automated fashion (i.e.: once configured, the system should continuously collect EN data unless interrupted by the user). Specifically, the equipment must be capable of making simultaneous measurements of both current and voltage EN at a recording rate of at least one (1) measurement per second. The equipment must be capable of making measurements on at least eight channels simultaneously. Multiplexed systems that read sequentially from channel to channel are not acceptable.

- In addition to being capable of collecting and analyzing EN data, the system must also be capable of periodically conducting linear polarization resistance (LPR) and Tafel scans. The corrosion monitoring system and system software must allow this periodic change. Preferably, the system will be configurable to allow the user to set up a time interval between LPR scans. For example, the system could be configured to collect EN data continuously, but once per month, stop the EN measurements, call out and run an LPR scan on each channel, then return to EN measurements.

- The physical location of the waste tanks in relation to power sources, phone lines, network drops and other necessary connections dictates that there will be up to 400 feet $(\sim 122 \mathrm{~m})$ of 20 -gauge wiring between the lowermost channels on the probe and the corrosion monitoring instrumentation. Each wire (one wire per channel) will pass through an MTL Model 755-AC shunt-diode type intrinsic safety barrier before passing into the corrosion probe body and down to its respective electrode. The maximum entity parameters for the MTL Model 755$\mathrm{AC}$ barriers are 40 microfarads capacitance and 0.125 millihenry inductance. The length of wiring from the barriers to the electrodes will be 100 feet $(\sim 31 \mathrm{~m})$ or less. The balance of the wiring runs from the intrinsic safety barriers to the corrosion monitoring instrumentation. With the long cable and intrinsic safety barriers in place, the system must be capable of current and potential resolutions of at least $\pm 1 \times 10^{-9} \mathrm{~A}$ and $\pm 1 \times 10^{-5} \mathrm{~V}$ respectively. Prior to contract award, the seller will be required to show evidence that their equipment meets these minimum sensitivity requirements given the aforementioned set-up.

- The in-tank corrosion probe that holds the electrodes in the waste is designed for eight total channels with three electrodes on each channel. The corrosion probe is fabricated from 1.0inch $(2.5-\mathrm{cm})$ diameter schedule XXS stainless steel pipe with an inside diameter just large enough to contain 24 conductors of 20 -gauge wire. The corrosion monitoring instrumentation must utilize a three wire per channel, eight-channel setup with simple 20 - 
gauge wires, as opposed to shielded coaxial cables, to make the connection between electrodes and instrument.

- The software that controls the corrosion monitoring system shall be compatible with standard Microsoft Windows ' 95 or Windows NT platforms. All EN and LPR data must be stored in a format compatible with ODBC and SQL databases to allow the user to export data to other user supplied analyses and presentation packages. Furthermore the corrosion monitoring system software shall be capable of performing and graphically presenting statistical analyses on the EN data, automatically calculating corrosion rates from LPR data, and calculating and presenting trends in the statistical analyses data. The corrosion monitoring system software must provide user configurable alarm points to notify the user of the onset of dangerous corrosion conditions within the waste tank. The software shall be configurable to allow full storage of all data all the time or to automatically discard data not recorded at a set interval of time on either side of an alarm event, thus minimizing the amount of EN data the user must evaluate.

Based on the responses to this RFP, an EN-based corrosion monitoring instrument manufactured by Petroleum Research Production (PRP), Ltd. was procured. The corrosion monitoring software used to drive the PRP instrumentation is entitled "Amulet" and is manufactured by Corrosion \& Condition Control $\left(\mathrm{C}^{3}\right), \mathrm{Ltd}^{4}$ This system was installed in 241-AN-102 in late FY 1998.

The heart of the Amulet software is inherently different than data collection/analysis tools used on previous systems. In contrast to the Gamry and CML software that focused primarily on data collection, Amulet is primarily a graphically driven data analysis tool and will accept data from almost any other source. Nearly all of the data manipulation operations manually performed in on Gamry and CML data are automated to a large degree in Amulet.

A separate software application shipped with Amulet is used to collect data from the PRP hardware. The data collection software (DataScan WeeGuy ${ }^{5}$ ) can be configured to collect EN data simultaneously from up to eight channels. The data collection software can also be configured to run periodic LPR scans on any set of electrodes used for EN data collection. Until stopped by the operator, data are continuously written to a database designed to be opened with Amulet.

Data storage is also quite different in the Amulet system as compared to the Gamry and CML systems. Both the Gamry and CML systems wrote small packages of data to numerous individual files over the course of operation. At the conclusion of testing, some manual method of stripping raw data out of the files had to be employed if statistical data were to be analyzed. This was no small task since over the course of even a few weeks both the Gamry and CML systems produced thousands of individual raw data files. In contrast, raw data collected on the Amulet system is continually time/date stamped and stored in a single database that uses the

\footnotetext{
${ }^{4} \mathrm{C}^{3}$ and Amulet are registered trademarks of Corrosion \& Condition Control, Ltd., Dingwall, U.K.

${ }^{5}$ DataScan WeeGuy is a registered trademark of Corrosion \& Condition Control, Ltd., Dingwall, U.K.
} 
same database engine as Microsoft Access. ${ }^{6}$ Therefore, the Amulet database is compatible with all other ODBC and SQL databases. Statistical data are stored in the same database with the raw data and all parameters can be plotted for comparison. The Amulet system also has a built-in archiving feature that allows the operator to compress and store historical data that is not used on a regular basis. This feature is especially useful limiting the amount of network hard drive space the 241-AN-102 system occupies.

Graphical analysis is provided directly in Amulet in near real-time with no need to export data to another spreadsheet program. Amulet allows simultaneous plotting and overlays of any real (measured) or derived parameters during testing or operation. A typical plot of current and voltage EN data created in Amulet is shown in Figure 11.
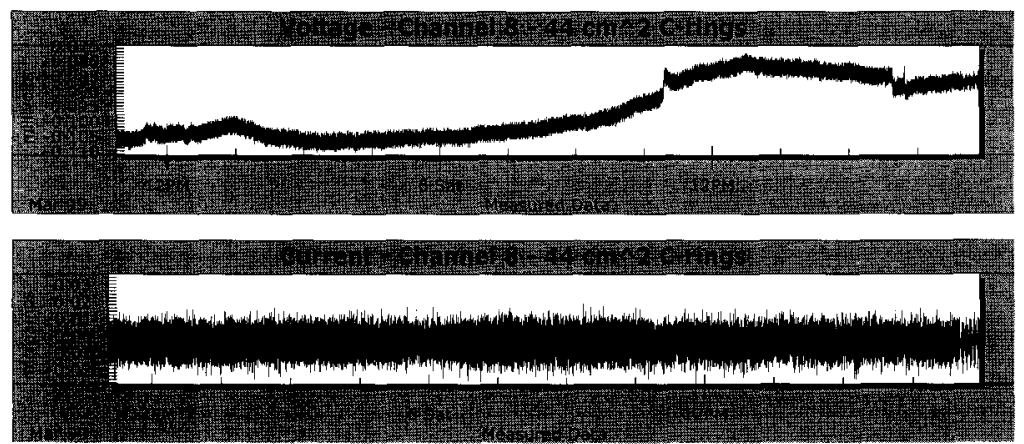

Figure 11: Amulet raw data plot showing current and voltage EN in 241-AN-102

The main user interface screen used to create plots of various parameters is shown in Figure 12. Several other options help automate and simplify data analysis. Some of the most useful features include:

- Simultaneous zooming or magnification of discrete time periods is allowed on multiple plots.

- Alarm levels for any parameter can be configured and displayed on any plot.

- Summary tables can be produced automatically for hour, day, week, or month blocks of data to limit the amount of data the user wants to look at.

- Plots can be annotated with short user notes or process conditions prior to printing or an electronic logbook can be associated with each plot to store longer pieces of information.

- Plot data can be exported directly from the graph package either as a picture in *.bmp or *.wmf format or as data in a format suitable for spreadsheets, other databases or word processors. Plots can also be exported using the clipboard.

\footnotetext{
${ }^{6}$ Microsoft and Access are registered trademarks of Microsoft Corporation, Redmond, Washington.
} 


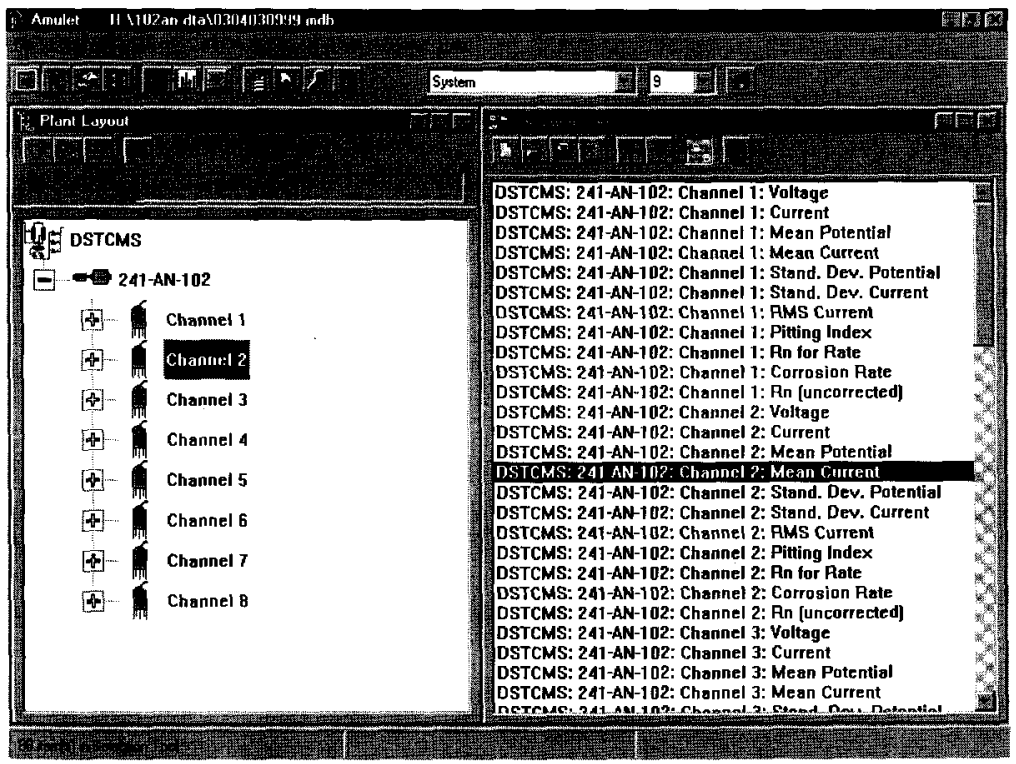

Figure 12: Main Amulet user interface screen

One of the most important features in Amulet is the ability to set alarm points to automatically notify an operator when a corrosion related parameter exceeds a certain level. Neither of the previous systems had this capability. When the alarm features are configured and enabled, Amulet constantly monitors data as they enter the system against the alarm set points. Two "above threshold" alarms (Alert and Alarm) and one "below threshold" alarm (Low Alarm) can be configured for any parameter. There are also high and low value validation checks used to detect hardware faults in the PRP instrumentation. If an alarm point is exceeded, a flashing alarm annunciation icon is displayed on the computer's monitor. This icon flashes until the appropriate alarm report is checked. There are a number of reports that can be automatically associated with alarms. On a daily basis the various counts of $\mathrm{OK}$, Alert and Alarm can be plotted in a trend. This feature could be used in the future to trend tank chemistry control performance.

In summary, the Amulet software has greatly improved the automation of waste tank EN data analysis. In contrast with previous systems, the Amulet operator no longer has to manually collect, sort and store thousands of raw EN data files. Amulet writes all data to a single database. With previous systems, statistical analyses were performed by manually stripping out data from thousands of raw data files and either calculating statistics in a spreadsheet format or 
running the raw data through a piece of internally developed statistical analysis software. In either case plotting and inspection were done manually in Microsoft Excel or other spreadsheet programs. Statistical analysis is automatically performed in Amulet while the raw data are being collected. Uniform corrosion rate calculations and other derived parameters had to be manually calculated in a spreadsheet format with data from the Gamry and CML systems. Rate and other derived parameters are defined by the user prior to data collection in Amulet and collected automatically once data collection is commenced. These and other improvements have greatly improved the speed at which EN data can be analyzed in addition to improving the quality of the final interpretation. Such improvements are not only nice, but inherently necessary if multiple tanks are to instrumented and analyzed.

\section{1-AN-105 CORROSION MONITORING SYSTEM}

The move from the Gamry and CML type systems to the Amulet/PRP system easily represents the largest step forward in automating the EN data analysis process. Although the 241-AN-102 corrosion monitoring system has been hampered by external data interference and other nonsoftware related problems, the obvious potential of the Amulet software has not been ignored. In FY 1999, a duplicate Amulet/PRP system was procured to be used for monitoring 241-AN-105. Design problems resulting in data loss and distortion in the 241-AN-102 system have been addressed in the 241-AN-105 system. This system is scheduled for installation in late FY 1999.

\section{FUTURE WORK AND WORK BY OTHERS}

To date, the corrosion monitoring development effort at Hanford has focussed on the analysis of raw EN data (current or voltage noise vs. time) and statistical analysis of this raw data (mean, standard deviation, etc. vs. time). Historical work by others and the development effort at Hanford have indicated a clear relationship between patterns of current and voltage noise and the mode of corrosion. However, other methods of EN data analysis can be employed including frequency domain analysis (fast Fourier transforms and/or maximum entropy method analyses) and the application of neural networks.

One of the most interesting data analysis techniques on the horizon is the potential to apply neural networks in the process of EN data analysis. Although EN-based corrosion monitoring is gaining wider acceptance within the corrosion monitoring and plant operation communities, a more succinct method of analyzing and interpreting the results of $\mathrm{EN}$ data is still needed. At present, interpretation of EN data still mandates detailed analysis by a corrosion expert to identify and categorize the mechanism of corrosion attack. If applied correctly, neural networks could de-skill the post-data collection procedure and broaden the range of users able to understand and interpret corrosion data. Additionally, neural networks would provide a consistent methodology for data analysis that would be less subjective and time consuming than analyses by corrosion experts.

Although the promise of applying neural networks to EN data is great, the technique is still in it's infancy with few researchers applying an effort in this direction [28,29]. However, ever increasing demands to operate plant environments safely and efficiently will likely drive the research in this field. Ultimately, the ability to de-skill data the data analysis process will make 
or break the use of EN as a plant monitoring tool on a wide scale. Recent advances in graphical analysis software and neural networks show promise in moving EN-based corrosion monitoring further into industry.

\section{SUMMARY AND CONCLUSIONS}

A project to improve the Hanford Site's corrosion monitoring strategy was started in 1995 . The project is designed to integrate EN-based corrosion monitoring into the site's corrosion monitoring strategy. In order to monitor multiple tanks, a major focus of this project has been to automate the data collection and analysis process. Data collection and analysis from the early EN corrosion monitoring equipment (241-AZ-101 and 241-AN-107) was primarily performed manually by a trained operator skilled in the analysis of EN data. Thousands of raw data files were collected, manually sorted and stored. Further statistical analysis of these files was performed by manually stripping out data from thousands of raw data files and calculating statistics in a spreadsheet format. Plotting and other graphical display analyses were performed by manually exporting data from the data files or spreadsheet into another plotting or presentation software package.

In 1999, an Amulet/PRP system was procured and employed on the 241-AN-102 corrosion monitoring system. A duplicate system was purchased for use on the upcoming 241-AN-105 system. A third system has been procured and will eventually be used to upgrade the 241-AN107 system. The Amulet software has greatly improved the automation of waste tank EN data analysis. In contrast with previous systems, the Amulet operator no longer has to manually collect, sort, store, and analyze thousands of raw EN data files. Amulet writes all data to a single database. Statistical analysis, uniform corrosion rate, and other derived parameters are automatically calculated in Amulet from the raw data while the raw data are being collected. Other improvements in plotting and presentation make inspection of the data a much quicker and relatively easy task. These and other improvements have greatly improved the speed at which EN data can be analyzed in addition to improving the quality of the final interpretation. The increase in data automation offered by the Amulet software is necessary if multiple tanks are to instrumented and analyzed at the Hanford Site.

Although advances in the automation of data analysis have been great, Hanford EN data analysis still demands a highly trained corrosion expert. Neural networks could de-skill the post-data collection analysis procedure and broaden the range of users able to understand and interpret corrosion data. Ultimately, the ability to de-skill data the data analysis process will make or break the use of EN as a plant monitoring tool on a wide scale.

\section{REFERENCES}

[1] R.K. Shukla, A.J. Perkins, P.M. Bourgeois, R.J. Jaramins, W.G. Secen, and, D.J. Stroud, Corrosion Monitoring of High Level Waste Storage Tank 8-D2 at the West Valley Demonstration Project, CORROSION/94, paper no. 121, (Houston, TX: NACE International, 1994). 
[2] D.C. Lini, Compilation of Hanford Corrosion Studies, Atlantic Richfield Hanford Company Report, ARH-ST-111, UC-70, July, 1975.

[3] G. L. Edgemon and R. P. Anantatmula, Hanford Waste Tank System Degradation Mechanisms Report, Westinghouse Hanford Company Report, WHC-SD-WM-ER-414, Rev. 1, October, 1996.

[4] T. Haygard and J. R. Williams, Trans. Farad. Soc. 57, (1961): p. 2288.

[5] P. Bindra, et al., Discussions of Faraday Soc. 56, (1974): p. 189.

[6] M. Fleischmann, et al., Surface Science 100-101, (1980): p. 583.

[7] G.J. Bignold and M. Fleischmann, Electrochemical Acta 19, (1974): p. 363.

[8] E. Budevski, et al., Electrochemical Acta 28, (1983): p. 925.

[9] G. Blanc, et al., Electrochemical Acta 23, (1978): p. 337.

[10] K. Hladky and J. L. Dawson, Corrosion Science 22, (1982): p. 231.

[11] U. Bertocci, Electrochemical Noise Analysis and Its Application to Corrosion, CORROSION/89, paper no. 24, (Houston, TX: NACE International, 1989).

[12] J.L. Dawson, D.M. Farrell, P.J. Aylott, and K. Hladky, Corrosion Monitoring Using Electrochemical Noise Measurements, CORROSION/89, paper no. 31, (Houston, TX: NACE International, 1989).

[13] D.A. Eden, A. N. Rothwell, and J.L. Dawson, "Electrochemical Noise for Detection of Susceptibility to Stress Corrosion Cracking, CORROSION/91, paper no. 444, (Houston, TX: NACE International, 1991).

[14] D.M. Farrell, Industrial Corrosion 9, (1991): p. 7.

[15] A.N. Rothwell, T.G. Walsh, and W.M. Cox, On Line Corrosion Investigation and Surveillance - Chemical Plant Case Studies, CORROSION/91, paper no. 170, (Houston, TX: NACE International, 1991).

[16] J.L. Dawson, et al., On-line Monitoring of Continuous Process Plants, ed. D. Butcher, (Ellis Horwood, NY, 1983).

[17] D.M. Farrell, W.M. Cox, and D. Gearey, Multi-System Corrosion Monitoring in a Cyclic Reheat Test Facility; Phase 1, Electric Power Research Institute Report, CS-5776, 1988.

[18] D.M. Farrell, W.M. Cox and D. Gearey, Multi-System Corrosion Monitoring in FGD Systems; Phase 2, Electric Power Research Institute Report, CS-5734, 1988. 
[19] B.C. Syrett and W.M. Cox, in: Proc. First Int. Symposium on Electrochemical Noise Measurements for Corrosion Applications, ASTM STP 1277, eds. J.R. Kearns, J.R. Scully, P.R. Roberge, D.L. Reichert, and J.L. Dawson, (American Society for Testing and Materials, Philadelphia, PA, 1996) p. 173.

[20] C.A. Lotto and R.A. Cottis, Corrosion 45, (1989): p. 136.

[21] G.L. Edgemon and G.E.C. Bell, Technical Basis for Electrochemical Noise Based Corrosion Monitoring of Underground Nuclear Waste Storage Tanks, Westinghouse Hanford Company Report, WHC-SD-WM-TI-772, November, 1996.

[22] G.L. Edgemon, J.L. Nelson, P.C. Ohl, and G.E.C. Bell, Hanford Prototype Corrosion Probe Operational Experience, CORROSION/97, paper no. 97124, (Houston, TX: NACE International, 1997).

[23] G.L. Edgemon, J.L. Nelson, and G.E.C. Bell, Design of an Electrochemical Noise Based Corrosion Monitoring Probe for High Level Nuclear Waste Storage Tanks, CORROSION/98, paper no. 98175, (Houston, TX: NACE International, 1998).

[24] G.L. Edgemon and J. L. Nelson, Design of Second-Generation Corrosion Monitoring Probe, Lockheed Martin Hanford Company Report, HNF-2517, Rev. 0, April, 1998.

[25] G.L. Edgemon and J. L. Nelson, Design of Multi-Function Hanford Tank Corrosion Monitoring System, Lockheed Martin Hanford Company Report, HNF-4285, Rev. 0, April, 1999.

[26] G. L. Edgemon, J. L. Nelson, P. C. Ohl, Prototype Corrosion Probe Four Month Status Report, Lockheed Martin Hanford Company Report, WHC-SD-WM-TI-796, Rev. 0, December, 1996.

[27] G.L. Edgemon, Tank 241-AZ-101 Prototype Corrosion Probe Two-Year Status Report, Lockheed Martin Hanford Company Report, HNF-3416, Rev. 0, September, 1998.

[28] S. Reid, Neural Analysis for the Categorisation of Corrosion Mechanisms, Senior Project for Dr. Jim O'Shea, Manchester City College, 1996.

[29] S. Reid, G. E. C. Bell, and G. L. Edgemon, "Application of Skewness and Kurtosis with Neural Networks to Analysis of Electrochemical Noise Data from Nuclear Waste Tanks," CORROSION/98, Paper No. 98176. 